\title{
De infinito a infinito: CARrera, Aira, ROSA $^{1}$
}

\author{
Bairon Oswaldo Vélez Escallón
}

Las geometrías espaciotemporales del cubismo, y los juegos mecánicos a los que dan lugar, no valdrían nada para el arte si les faltara la poesía. (César Aira, Triano, 2013)

\section{TRIANO: COSMOLOGÍAS, COSMOGONÍAS, ECONOMÍAS}

La novelita se llama Triano. Está datada en 2013, pero la "aventura" narrada se remonta a mediados de los años 6o, la juventud de sus protagonistas, entonces con 16 o 17 años. Son dos poetas, cuyos nombres hoy son bastante conocidos, así como el nombre de su lugar de origen, escenario de la novela. El lugar es Coronel Pringlesy los poetas adolescentes son Arturo Carrera y César Aira.

La trama es bastante simple: los jóvenes César y Arturo han ido a un comercio local "a comprar cinta adhesiva", para montar al día siguiente una "Exposición de Poemas Ilustrados" (AIRA, 2014b, p. 7). Quisiera

1 El presente trabajo es la versión detallada de una ponencia presentada en Boston en marzo de 2016, en el marco del evento Annual Meeting of the American Comparative Literature Association (ACLA- Harvard University, Cambridge, Massachusetts). Es una derivación de algunos de los temas, presupuestos y problemas concernientes a la investigación "Borges, Guimarães Rosa e a quarta dimensão", que desarrollé, en instancia posdoctoral, en el Posgrado en Literatura de la Universidad Federal de Santa Catarina, con supervisión de la Profa. Dra. Susana Scramim, entre 2014 y 2016. Además de a la profesora Scramim, agradezco los comentarios y sugerencias de Joaquín Correa y Joca Wolff. 
destacar que, ya en su inicio, esta narrativa pone en escena algunas de las cuestiones que serán abordadas en este trabajo: el montaje (la cinta adhesiva), la superposición entre imagen y texto, o la conjunción de artes del lenguaje y artes visuales (los poemas ilustrados), supuestamente separables como campos autónomos según una vasta tradición crítica. Aún hay otra cuestión, que podríamos denominar "cosmológica”, y que se desarrolla extensamente en la novela a partir del momento en que Arturo y César encuentran por casualidad, en la librería a la que han entrado para comprar la cinta adhesiva, al pintor cubista y fotógrafo cuyo nombre da su título a la novela: José Triano. ${ }^{2}$ Es el único artista de Pringles y un objeto de admiración para los jóvenes poetas, que inmediatamente lo informan de la Exposición de Poemas Ilustrados, queriendo saber su opinión al respecto. Para animarlos en la iniciativa, Triano, que "adhería [como la cinta adhesiva] a la escuela cubista” (p. 13), los lleva a su taller, y también para iniciarlos en "la investigación del misterio del espacio en la representación" (p. 14).

Los dos poetas se sienten ridículos, pues saben que sus ilustraciones son "mamarrachos pintados de apuro en una semana" y que los poemas no pasan de breves composiciones "más o menos mal imitadas de las de Alejandra Pizarnik” (AIRA, 2014b, pp. 15-16). ${ }^{3}$ Sin embargo, aceptan la invitación de Triano y pasan a escuchar de su boca, en el atelier del artista, la doctrina cubista ${ }^{4}$ (pese a que los dos jóvenes se sienten más cercanos al

2 Reproduzco, al respecto de José Triano, la nota no 21 del ensayo "Poesia e vida em Arturo ou Câmbio de ideia no 2 ou Lo creo porque es absurdo", de Jorge Wolff (2016, p. 58): "Arturo Carrera fornece-lhe nome e sobrenome ao dar conta da existência do fotógrafo e pintor, em texto lido em La Plata em 2008. Em 'Canon, lo banal, lo perdurable en la escritura', o poeta afirma que 'de Oliverio Girondo y de Juan L. Ortiz me habló don José Triano, un pintor discípulo de Petorutti que había llegado a Pringles y que fue amigo personal de Juanele. De modo que él nos hizo entrar en su mundo, digo nos hizo porque incluyo a César Aira, que por ese entonces ya era amigo mío'. Disponível no blog Tuerto Rey. Poesía y alrededores: <http://www.tuertorey.com.ar/php/autores.php?idAutor=66>. Agradeço a indicação a María Florencia Antequera”.

3 Sobre la relación entre Pizarnik y Carrera, no por casualidad estudiada en relación con modelos económicos, cf. Correa (2016).

4 ¿Qué es el Cubismo? En sus inicios un nombre nacido del sarcasmo de algún crítico, alguien que tal vez diría: “¡Pero estos son cubos nada más! Una pila de cubos, cubos desparramados en la tela. ¡Estos pintores son unos 'cubistas', ja ja ja”. Posteriormente un nombre apropiado por los propios artistas objeto del sarcasmo, que lo usan en adelante como "prenda de honor y estandarte de combate" (AIRA, 2014b, p. 25). Tal vez no sea ocioso recordar aquí, en provecho de lo que vendrá más adelante, que aspectos formales y temáticos del Cubismo confluyen hacia una tendencia etnográfica y que, en relación con las temporalizaciones del espacio, o espacializaciones del tiempo, permitieron a Duchamp, Remate de Males, Campinas-SP, v. 37, n. 1, pp. 345-367, jan./jun. 2017 
Surrealismo). Superposiciones de planos, espacios de la representación que se precipitan hacia su propio interior, geometrías de otros mundos, componen las pinturas que decoran el atelier del pintor, y sirven de ambiente a la iniciación que compone la línea narrativa principal de la novela: "el triunfo de la imagen, la verdadera, la que viene del fondo del discurso" (p. 32).

Luego de algunos prolegómenos, Triano llega a su tema central: dos teorías opuestas sobre el origen del Universo: el Big Bang, o "hipótesis de Lemaitre", y el Steady State, o "estado estable", postulado por Fred Hoyle. La oposición entre estas teorías cosmológicas es, singularmente, cosmogónica:

[...] la "hipótesis de Lemaitre" [el Big Bang] postula la expansión a partir de un momento dado, un momento que es un punto (simplificando), momento y punto que son el origen a partir del que empiezan a formarse el espacio y el tiempo. Es decir que postula un inicio para todo. La teoría opuesta, llamada por su principal expositor, Fred Hoyle, “estado estable”, afirma que el Universo es eterno y que podemos descartar cualquier idea de comienzo (AIRA, 2014b, p. 26).

Mientras que la hipótesis del dignatario de la Compañía de Jesús Georges Lemaitre, aclara Triano, puede significar un retorno del creacionismo y del "nefasto concepto de Dios", el Steady State entiende que la expansión del universo "podría ser como la de un río que fluye sin dejar de ser eterno (AIRA, 2014b, pp. 26-27). Es decir, mientras que el Big Bang puede recolocar en vigencia la idea de Una Historia, que para ser una historia de la salvación debe ser unilineal, partir de un único inicio y dirigirse a un único fin, el "estado estable", como Borges (2010, p. 133), nos dice que: "El tiempo es la sustancia de que estoy hecho. El tiempo es un río que me arrebata, pero yo soy el río; es un tigre que me destroza, pero yo soy el tigre; es un fuego que me consume, pero yo soy el fuego. El mundo, desgraciadamente, es real [...]".

Con otras palabras, mientras que el Big Bang puede postular la previsibilidad de los eventos, puesto que están remitidos a un origen único y determinado, el "estado estable" trata de lidiar con el misterio de

a Picasso o a Carl Einstein relativizar y hacer extraña la centralidad, y la unicidad, de las culturas europeas de referencia. Para tener una idea de ese debate en el momento de las vanguardias, y concretamente del Cubismo, entendido como un descubrimiento del "pluralismo dos espaços específicos", cf. Einstein (2016). En relación con Duchamp, cf. Antelo (2010). Sobre Einstein, cf. Antelo (2016); Lahuerta (2015); Didi-Huberman (2006). Sobre la cuestión etnográfica en relación con las vanguardias, cf. Clifford (2008).

Remate de Males, Campinas-SP, v. 37, n. 1, pp. 345-367, jan./jun. 2017 
un origen no definible y a partir de ese misterio, con una proliferación de existencia que si bien es evidente, no se puede capturar en una cosmología. Estamos, por lo tanto, delante de dos modelos que no son solamente cosmológicos y cosmogónicos: también son modelos económicos. En un caso, domina la especulación y la acumulación; en el otro, reina el dispendio y el exceso de ser. 5 Un real que, desde luego, nunca para de no escribirse y que puede traducirse a través de un "relato visual" en que proliferan en simultaneidad vistas no simultáneas de los mismos objetos. Mientras que el relato unilinear naturaliza el tiempo, el Cubismo lo intelectualiza como espacio, pues con "voracidad fluída y constante" (AIRA, 2014b, p. 33), devora los planos de la experiencia y los representa juntos, dando cuenta tanto de la artificialidad de su intervención como de la misma convencionalidad de la representación, digamos, realista, la representación perspectivista (p. 36). En un modelo domina la falta, en el de Triano, el cubista del Steady State, domina el deseo: "Porque el espacio nunca está completo sin el tiempo, y cuando la suma de los dos está bien hecha el resultado es la eternidad" (p. 51).

No me puedo extender más sobre Triano y quisiera ahora simplemente que retuviésemos estos elementos: el deseo, la indecidibilidad entre espacio y tiempo (cara a las teorías de la cuarta dimensión), ${ }^{6}$ el exceso o proliferación del significante que lo acerca o lo indistingue de la imagen por su artificialidad y por su carácter de constelación "montada", la situación -Coronel Pringles- en que un pintor de pueblo explica para dos poetas adolescentes de pueblo el Gran Preliminar del Cubismo, también cosmológico: el viaje a la redondez de la Tierra, que Triano ilustra a través

\footnotetext{
5 Me refiero, claro está, a los modelos propuestos por Georges Bataille (2009) en La parte maldita de 1949. En "Sobre o surrealismo etnográfico", James Clifford (2008) da una idea del diálogo entre las reflexiones sobre la noción de dispendio de Bataille y el pensamiento de Carl Einstein, así como sobre la deuda común con el pensamiento del maestro-donador Marcel Mauss.

6 Como se intentará desarrollar más adelante, esa indecidibilidad también se relaciona con cuestiones "identitarias" o "situadas", que descentran al individuo y vinculan la producción artística con agenciamientos colectivos. Eso es evidente en el Manifiesto dimensionista (1935), suscrito, entre otros, por Ben Nicholson, Alexander Calder, Vicente Huidobro, Joan Miró, Moholy-Nagy, Hans Arp, Pierre Albert-Birot, Robert y Sônia Delaunay, Marcel Duchamp, Wassily Kandinsky y Francis Picabia. Ese manifiesto reivindica que : "l'art à n+1 dimension' (le planisme) se soucie peu de la destinée individuelle. Parce que la signification de la vie individuelle s'efface et perd le privilège de la véritable existence par suite de la libre association du temps et de l'espace" (apud ANTELO, 2012, p. 46). En relación con las teorías de la cuarta dimensión y lo que se denominó antes como un "cosmopolitismo situado" en Borges y Guimarães Rosa, cf. Vélez Escallón (2015; 2016).
}

Remate de Males, Campinas-SP, v. 37, n. 1, pp. 345-367, jan./jun. 2017 
de la historia de dos monjes que, partiendo de posiciones antípodas en una ascensión al cielo astronómico, uno partiendo de la horizontal, el otro de la vertical, acaban encontrándose en el cielo-paraíso, el cielo cubista, pues la coincidencia entre las líneas horizontales y las verticales "es la definición de santidad": "los cielos antípodas son el mismo cielo, donde los buenos artistas son juzgados según hayan podido o no poner en su cuadro la sexta cara del cubo" (AIRA, 2014b, p. 63). ${ }^{7}$

\section{DESCAMINOS COSMOLÓGICOS}

Aira y Carrera, como los dos monjes-astronautas de la historia, partieron de la misma tierra, aunque sus trayectorias se fueron separando al subir. Uno es poeta, el otro predominantemente un narrador. Sin embargo, si continuamos un poco el delirio tetradimensional de Triano, y si para eso recordamos a Ouspensky, un teórico de la cuarta dimensión muy frecuentado por Borges y por Guimarães Rosa, podríamos decir que esos dos monjes son el mismo monje, pues no sólo nacieron por los mismos tiempos en el mismo lugar. En la cuarta dimensión, postula Ouspensky, espacio y tiempo no pueden pensarse como existencias separadas. Por hacer parte de una realidad incognoscible, según el Tertium Organum (1912), todas las cosas estarían entre sí en una relación de absoluta identidad: todos los hombres serían un solo hombre y todos los libros un solo libro (VÉLEZ ESCALLÓN, 2015). Con Triano, podríamos profetizar retrospectivamente al respecto de Aira y Carrera:

[...] gracias a ustedes dos se hará la reunificación de las dos iglesias cismáticas, la de la Poesía y la de la Prosa. La Poesía sin la cual el arte sólo es vanidad, y la Prosa que crea los sueños de los que nacen los artistas (AIRA, 2014b, p. 67).

Hablando de iglesias cismáticas, vale la pena pensar, a partir de los indicios dejados por Aira en Triano, en los caminos, o puentes, a través de los cuales nuestros dos adolescentes pringlenses llegan a Guimarães Rosa. Es el tema de este trabajo.

7 Es importante recordar que, a su llegada a Buenos Aires, Aira y Carrera editaron, entre 1968 y 1969, la revista El Cielo, con sólo tres números publicados y colaboraciones de, entre otros, Severo Sarduy, Alejandra Pizarnik, Arturo Carrera, César Aira, Luis Felipe Noé, Marta Minujín y Edgardo Cozarinsky. Debo esta información a Joaquín Correa, a quien agradezco.

Remate de Males, Campinas-SP, v. 37, n. 1, pp. 345-367, jan./jun. 2017 
Como recuerda Gonzalo Aguilar en un ensayo dedicado a las narrativas El vestido rosa (1984) de Aira, y "O recado do morro" (1956) de Rosa, la llegada oficial de Guimarães Rosa a los lectores hispanoamericanos se dio en 1967 a través de la traducción de Grande Sertão: veredas (Ángel Crespo, Seix-Barral) y de los ensayos de dos críticos casi orgánicos del denominado boom latinoamericano: Luis Harss (1966) y Emir Rodríguez Monegal (1969). En los trabajos de esos críticos es posible identificar algunas constantes problemáticas: 1 ) hacen de autores como Rosa y Rulfo las "dos piedras miliares" de las letras de América Latina de ese momento; 2) lo que determina ese carácter precursor es la fidelidad representativa de los autores en relación a sus respectivos "lugares" de nacimiento; 3) también una afirmación vanguardista de la tradición, que pasa por la universalización de lo regional, es decir, por la representación de la esencia o "alma nacional" en un mercado internacional de formas simbólicas. Para Monegal, singularmente, Rosa sería la demostración de una síntesis histórica, de la superación de la oposición entre cosmopolitismo y regionalismo, eso por la vía de un experimentalismo heredado de las vanguardias modernistas brasileñas. En pocas palabras, Harss y Monegal fabrican un Guimarães Rosa que existe como preparación al boom mercadológico posterior, pero su singularidad se agota en esa precedencia (AGUILAR, 2000, p. 123 et ss.).

Las lecturas de esos críticos son resonancias del sistema de análisis -elaborado para Grande sertão: veredas- que ya en el ensayo "O homem dos avessos", de Antonio Candido (1957), se sustentaba en la contradicción entre "o mito e o logos; o mundo da fabulação lendária e o da interpretação racional” (CANDIDO, 1991, p. 309, grifo do autor). Ese sistema se desarrollaría, en la obra posterior del importantísimo crítico brasileño, en la teorización de un "superregionalismo" latinoamericano (CANDIDO, 1987, 2002) -del cual serían ejemplares las obras de Rulfo, Vargas Llosa y Guimarães Rosa-. También tiene resonancias en la que podríamos leer como la respuesta culturalista al vanguardismo cosmopolita de Monegal, cuya balanza siempre pende para el lado de un cosmopolita "neutro". Hablo de la Transculturación narrativa de Ángel Rama (1983), en cuyo caso el foco está sobre la identidad producida por la tensión entre instancias culturales diversas que, por su parte, son transformadas por una cosmovisión subalterna, lo que significa que la complejidad viva y dinámica de lo literario es comprendida como un desafío a las nociones de tercer mundo y subdesarrollo, pero la singularidad textual continúa 
obliterada por la transmisión de un significado esencial o nuclear que no puede dejar de estar inmóvil para ser descrito. En ese sentido, Rosa sería una especie de continuador transculturador del regionalismo.

Más que agotar aquí esas colocaciones críticas, me interesa destacar en ellas un núcleodesentidocomún. Podríamosdecirqueson manifestaciones de una economía restringida, así como de eso que Derrida (1991, p. 352) llama "metafísica de la presencia" o "modificación (ontológica) de la presencia”. Economía restringida: es decir, en que dominan la especulación y la acumulación en vista de necesidades específicas (construcción de una tradición, definición de un canon nacional o continental, inserción de un discurso crítico a través de su participación en los debates del campo etc.). Metafísica de la presencia: es decir, una postergación del texto que busca establecer significados en un más allá de palabras apenas representativas, precisamente porque si dominan la especulación y la acumulación, esos significados deben fijarse de acuerdo con una "utilidad" (sea la creación de precursores o tradiciones prestigiosos para escrituras actuales, sea la superación de impases teóricos que manifiestan fuertes antagonismos vitales en un continente relativamente joven, sea la postulación de una consciencia literaria dilacerada del subdesarrollo). Entonces, resumiendo, podríamos decir que lo que caracteriza estos protocolos es su participación de los presupuestos de un paradigma representacional, de un concepto de historia lineal y de una economía restringida a la necesidad.

Otra, me parece, es la tradición crítica y teórica a la que Aira remite en Triano. Creo que esa otra tradición se pauta por el deseo y no por la necesidad, que fija su atención sobre el gesto (el mimetismo) y no sobre la mímesis, y que desconfía de una noción progresiva de la temporalidad. En el caso de Triano, creo que la referencia a Bataille (1949) es casi explícita y que el tipo de economía a que se reporta esa otra tradición crítica que mencioné es una economía general en los términos de La parte maldita. Una economía del potlatch, que Aira (1990, pp. 61-62) define así en Los fantasmas:

El desarrollo de la arquitectura "real", es decir de los elementos decorativos, está directamente ligado con la posibilidad de acumular provisiones para los trabajadores o esclavos que hacen el trabajo, que lo hacen sin tener tiempo de ir a cazar o a recoger comida. Esas acumulaciones inciden en la desigualdad. Un mecanismo que se usa para aminorar los excesos de acumulación, y regular la riqueza ( $\sin$ regulación no habría riqueza), es el potlatch, la fiesta en la que se derrocha toda clase de comida y bebida y otros elementos, en un gasto loco, momentáneo, que vuelve las cosas a su nivel deseable. La fiesta, asociada a las formas temporarias o perecederas del arte, cumple con su fulgor 
y su abundancia la función de atraer a la mayor cantidad de gente posible; la cantidad es necesaria a su vez para que la manifestación artística, que no va a permanecer en el tiempo, sea apreciada por el mayor número posible. Hay una economía inherente a la manifestación artística, en todas sus formas, y ésta es la que se da en este caso.

Claro que el potlatch es todavía la prehistoria de la fiesta, su genealogía podría decirse, porque con el tiempo debe surgir la alternativa de que no se haga presente más gente sino gente especial, la gente que importa, sutilización de la sociabilidad. El fin lógico de este proceso es la fiesta unipersonal, de la que el sueño es el modelo más acabado

No es una coincidencia. De hecho, Aira (2003, p. 91) y Raul Antelo (2008, p. 257) coinciden en la apreciación de que la poesía de Carrera es una poesía de la deixis ${ }^{8}$, del dedo que señala, una poesía del gesto, que escribe huellas más que representar referentes originales. Aira no está lejos de esto, pues como sabemos ha sido insistentemente leído como un autor-performer, ${ }^{9}$ alguien que construye una figura de autor que se pauta por gestos y puestas en escena de su leyenda personal.

Creo que los gestos son siempre gestos del deseo y que, antes de la referencia a Bataille, importa pensar que la conexión entre esos autores y Guimarães Rosa se da por las vías del concretismo brasileño ${ }^{10}$-Noigandres

8 Para el caso de "O recado do morro", José Miguel Wisnik en "Recado da viagem" (1998) hizo una lectura semejante: la narrativa, para Wisnik, sería una especie de parábasis, en que se piensan los modos de transmisión y lectura de un mensaje, cuya significación, más allá de las palabras, depende de los contextos enunciativos y de los gestos no-verbales de la interacción de locutores y receptores.

9 La fortuna crítica de la obra de Aira al respecto de esa performatividad, que no raramente se sustenta sobre la (auto) fabricación de la figura del autor, con la consecuente puesta en crisis de la noción moderna de autonomía, es numerosa. Por esta razón, apenas remito a algunos de los trabajos que tratan directamente ese carácter o a aquellos que lo abordan desde perspectivas afines: Laddaga (2007), Klinger (2007; 2008), Wolff (2014), Premat (2009), Santos (2014), Ludmer (2007; 2010), Contreras (2002).

10 En Continuación de ideas diversas, Aira (2014a, pp. 29-31) se refiere al concretismo: "En los años setenta, entre mis amigos escritores se hablaba con admiración de la poesía concreta de los brasileños, y del Coup des dés de Mallarmé, que era su mito fundacional. Todos coincidíamos en que era una innovación valiosa, y asentíamos a su soporte teórico. Muy bien. Yo aceptaba todo eso, que la linealidad convencional de la vieja literatura debía romperse, la página constelarse, que había que liberarse de la apolillada sintaxis del discurso banal y dejar que las palabras hicieran el amor (recuperando el prestigioso slogan surrealista), que la escritura se hiciera escritura de verdad y no transcripción fonocéntrica del lenguaje, etc., etc., etc. Pero al mismo tiempo, sin renunciar a mi aceptación de estas ideas de ruptura creativa, encontraba pobres sus resultados. No estaba dispuesto a renunciar a tanto. Podía escribir algo así en términos de juego de salón, no en los de mi vocación, entonces en ciernes, de escritor. De ahí que me pregunte si no sería posible 'traducir' esas actitudes, sin traicionarlas (y hasta radicalizándolas más todavía), al idioma de la vieja literatura que decidió nuestra vocación". Vale la pena recordar que, al respecto Remate de Males, Campinas-SP, v. 37, n. 1, pp. 345-367, jan./jun. 2017 
y las Galaxias de Haroldo de Campos fundamentalmente- y de las intervenciones críticas de Severo Sarduy." Incluso si no damos atención a las referencias constelacionales de esos protocolos, no sobra constatar que todo protocolo de lectura es una especie de modelo cosmológico. Como muy bien lo comprendieron Sarduy (1999) y Silviano Santiago (1978) -y claro está, no sin recurrir al expediente de modelos cosmológicos íntimamente relacionados con protocolos o paradigmas de lectura profundamente marcados por sus lugares y tiempos de producción-, los peligros de una pretensión universalista, aunque etnocéntrica, sólo son superables si cada manera de leer manifiesta su situación, sus materiales de fabricación y su temporalidad singular, es decir, su artificialidad, su ficcionalidad. Es decir, toda constelación -teórica, crítica, canónicadepende de un marco de referencia, y cuanto más explícito es ese marco, más se evidencia el dinamismo y el carácter imaginario del conjunto.

En el caso de Sarduy, me parece, la conexión es evidente. Recordemos que es en parte con modelos cosmológicos que Sarduy (1972) estructura su ensayo sobre el barroco. Steady State y Big Bang, particularmente, culminan una de las partes de un ensayo que pasa por la elipse de Kepler, por Copérnico, por el geocentrismo, por Galileo, por Einstein. No por una coincidencia, la distinción que Sarduy (1999, pp. 1.248-1.249, grifos do autor) marca entre Steady State y Big Bang coincide punto por punto con la anteriormente citada de Triano:

La obra isomórfica del Steady State -corresponde a esa constitución formal $H$, de Philippe Sollers-, impugnaría no el dato científico, la comprobación, hoy observable, de la expansión, sino su fundamento teológico, tan aparente como el que sustentaba el círculo de Galileo y cuyo substrato humanista informa cada una de sus resonancias, como lo hacía la órbita "perfecta" en la organización de los tondi renacentistas.

de esa filiación, Luiz Costa Lima (2009, p. CCXX) manifestaba en 1963 un horror vacui ante Primeiras estórias (ROSA, 1962), cuyo barroquismo el crítico condenaba en términos de alienación de la realidad y como una "absorção por Guimarães Rosa da prática dos poetas concretistas". Años después, con la publicación del ensayo "A linguagem da crítica”, una presentación del libro Metalinguagem (1967) de Haroldo de Campos, el mismo Costa Lima volvería un poco sobre su apreciación inicial, al destacar la interpretación haroldiana de "Meu tio o Iauaretê" por mostrar "como nesta estória Guimarães Rosa alcança o realismo por via não tradicional, através de uma estratégia exclusivamente de linguagem” (COSTA LIMA, 1968, [s.p.]). Ese artículo se encuentra en el acerbo Guimarães Rosa del IEB/USP, catalogado con el código JGR-Rdc10-021.

11 Además de las conexiones que trataré de mostrar en este trabajo, Aira, Sarduy, Haroldo y Carrera aparecen como donadores de los epígrafes "ARTAUD” del delirio barroco titulado La partera canta, de 1982 (Cf. CARRERA, 2014, p. 317).

Remate de Males, Campinas-SP, v. 37, n. 1, pp. 345-367, jan./jun. 2017 
Quizás no sea un azar que la formulación del big bang se deba, como muchas de las teorías que suscitaron el barroco, a un dignatario de la compañía de Jesús: el abate belga Lemaitre; quizás su fundamento teológico esté presente en todo su enunciado: un estadio de génesis, puntual, metáfora del verbo y el semen/un estadio de crecimiento, metáfora de la multiplicación, del núcleo primigenio diseminado, pero también de la corrupción y del exilio/un apagón apocalíptico final, disolución en el vacío, ausencia del sentido.

Tal vez no sea ocioso recordar que Sarduy escribió a partir de 1970 el poemario Big Bang, o que "La noche escribe", el prefacio de Escrito con un nictógrafo (1972) es del mismo Sarduy,12 ni que Arturo Carrera en el dorso del esquema Momento de simetría, de 1973, declara que la "figura"13 surgió "de la contemplación de un gráfico de Fred Hoyle, de su conferencia sobre el estado estable" (2005, [s.p.]). ${ }^{14}$ Carrera también cita el ensayo "Barroco y neobarroco" (publicado por Sarduy en 1972 en el libro América Latina en su literatura, organizado por César Fernández Moreno), para destacar la búsqueda del objeto parcial, el objeto (a) lacaniano, ese objeto de deseo infinito y no alcanzable que justifica, o no, la proliferación significante del barroco y su fascinación por el suplemento y por lo fragmentario (pues son indicios de una totalidad imposible aunque anhelada), ese objeto que se resiste a pasar la línea, o el espejo, de la Alteridad, que se representa con una A mayúscula, que Sarduy denomina Alicia y alicia' ${ }^{15}$ de los dos lados

12 Severo Sarduy (2014, p. 540) en ese prefacio evidencia la apropiación de Carrera de la máquina carrolliana y del procedimiento de Raymond Roussel: "Escribiendo en lo oscuro, con su caja de hacer textos, infalible como las máquinas de Locus Solus, escribiendo en lo oscuro, iluminado sólo por la luz mortecina, cenicienta, de su Enana Blanca -la de los pies de paloma- Arturo Carrera nos muestra la galaxia negra, la que centra -cenit- el mediodía, su reverso: el día cegador de medianoche”. No olvidemos que Aira publicó un ensayo fundamental sobre el procedimiento Roussel (de hecho, este es tema recurrente en Aira) en el número 2 de Carta (Madrid: primavera-verano de 2011) (Cf. AIRA, 2016). Para una aproximación entre el procedimiento de composición de "Páramo", de Guimarães Rosa, y el de Locus solus, cf. Vélez (2014, p. 484 et ss.).

13 Carrera (1973) se refiere así a Momento de simetría, e inclusive destaca con cursivas esa palabra en el dorso del esquema.

14 "El poeta (cuando existe) y la poesía (su señorío) no pueden desdeñar las ciencias, sino acicatearlas con su mismo deseo. Aunque no sepa cuál es o qué es el deseo. Todo el asombro está contenido en la poesía. En el origen." (CARRERA apud ANTELO, 2008, p. 259).

15 "El objeto (a) en tanto que cantidad residual, pero también en tanto que caída, pérdida o desajuste entre la realidad (la obra barroca visible) y su imagen fantasmática (la saturación sin límites, la proliferación ahogante, el horror vacui) preside el espacio barroco. El suplemento [...] interviene como constatación de un fracaso: el que significa la presencia de un objeto no representable, que se resiste a franquear la línea de la Alteridad (A: correlación biunívoca de (a)), (a)licia que irrita a Alicia porque esta última no logra hacerla pasar del otro lado del espejo" (SARDUY, 1999, p. 1.402).

Remate de Males, Campinas-SP, v. 37, n. 1, pp. 345-367, jan./jun. 2017 
del espejo, y que se transforma en las dos A’s (Arturo y Alejandra Pizarnik) que preceden el título de Momento de simetría y cuyo esquema en espejo despliega esa duplicidad.

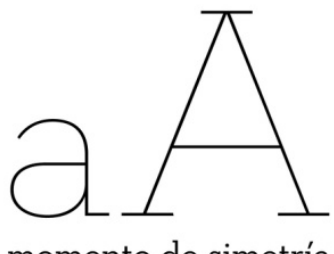

momento de simetría

ARTURO CARRERA

Figura 1. Carátula de Momento de simetría (CARRERA, 1973, [s.p.]).

Ahí entra Guimarães Rosa. Recordemos que para Sarduy, en los referidos ensayos, el espacio de las escrituras barrocas es el de la superabundancia y el desperdicio, que ese espacio constituye una especie de giro copernicano en las letras latinoamericanas, y que, precisamente, Grande sertão: veredas (obra de "exuberancia barroca", Ser-tão) se cuenta entre las experiencias convocadas por el teórico cubano para ejemplificar ese giro, que significa "la impugnación de la entidad logocéntrica que [...] nos estructuraba desde su lejanía y autoridad” (SARDUY, 1999, p. 1.404), es decir, de la historia entendida como una homogeneidad progresiva, imposición que el occidente moderno elevó a fundamento epistémico incontrovertible. El ejemplo que Sarduy toma de Grande sertão: veredas es el del significante "diablo", que el narrador evita, sustituyéndolo por una serie proliferante de designaciones que sólo aumentan su potencia demoniaca (p. 1.391). No vale la pena ver ahora esas citaciones, pero sí recordar que en los extremos del eje horizontal de Momento de simetría, Carrera traza signos que están en los extremos de Grande sertão: veredas, que le sirven de marco, también: 


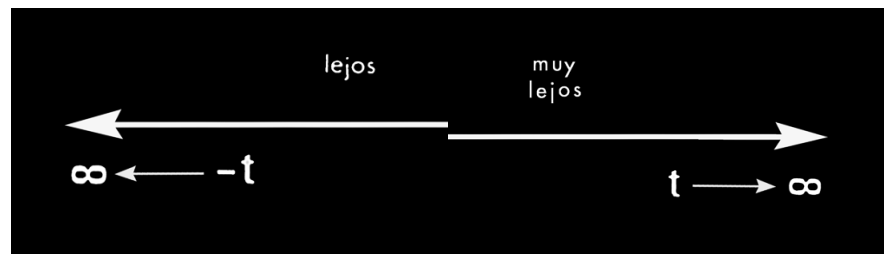

Figuras 2 y 3. Fragmentos de Momento de simetría (CARRERA, 1973, [s.p.]).

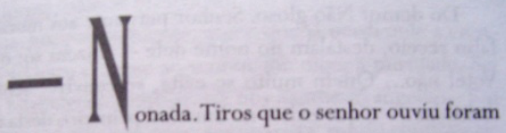
de briga de homem não, Deus esteja. Alvejei mira em árvore, no quintal, no baixo do córrego. Por meu acerto. Todo dia isso faço, gosto; desde mal em minha mocidade. Daí, vieram me chamar. Causa dum bezerro: um bezerro branco, erroso, os olhos de nem ser - se viu —; e com máscara de cachorro. Me disse-

Cerro. O senhor vê. Contei tudo. Agora estou aqui, quase barranqueiro. Para a velhice vou, com ordem e trabalho. Sei de mim? Cumpro: O Rio de São Francisco que de tão grande se comparece - parece é um pau grosso. em pé, enorme... Amável o senhor me ouviu, minha idéia confirmou: que o Diabo não existe. Pois não? O senhor é um homem soberano, circunspecto. Amigos somos. Nonada. O diabo não há! Ê o que eu digo, se for... Existe é homem humano. Travessia.

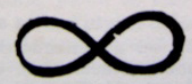

Figuras 4 Y 5. Fragmentos de Grande sertão: veredas (ROSA, 1976, pp. 9 y 460).

De la línea, con inicio, medio y fin, al infinito de la lemniscata. De alfa a omega. ${ }^{16}$ De la economía restringida de la acumulación a la economía general del oro o del excremento, de la falta al deseo, de la mímesis al mimetismo. ${ }^{17}$ Precisamente, como postula Raúl Antelo (2008, p. 253) en

16 José Miguel Wisnik (1998, p. 165), retomando un ensayo de Heloisa Vilhena sobre "O recado do morro", destaca la grafía oscilante del nombre del explorador alemán Seu O/ Alquiste como una especie de totalización entre los extremos alfa y omega, del alfabeto griego y de una vasta tradición alquímica. Si vamos al esquema Momento de simetría, al cuadrante izquierdo, en la parte superior, veremos alfa y omega en estos versos: "O /es teaxtro/ es estar/ fuera de la/ A" (CARRERA, 1973, [s.p.]).

17 Paradójicamente, tanto en Grande Sertão: veredas como en Momento de simetría, los signos que enmarcan el texto pueden leerse como indicios de la dimensión significante vaciada y como convenciones alegóricas del deseo. En Momento de simetría, las dos A's que preceden al título (Figura 1) remiten al objeto (a), pero también a Arturo y Alejandra. En Grande Sertão: veredas, los signos - y $\infty$, guión y lemniscata, remiten a la situación narrativa y tienen valores simbólicos ampliamente estudiados, pero también, si se vincula la lemniscata con la dedicatoria -"A Aracy, minha mulher, Ara, pertence este livro"-, y si se tiene en cuenta el nombre completo de la esposa del escritor -Aracy Moebius de Carvalho-, se puede percibir una referencia íntima, pues la lemniscata recuerda la forma de la cinta de Moebius. 
Crítica acéfala, la verdad de Carrera es "La verdad del tiempo reversible". Cito a Antelo (2008, p. 253):

[...] observaba Lamborghini que en Arturo Carrera el olvido del atributo histórico es deliberado, en tanto su poesía quiebra "la mitomanía de la sucesión, el origen, el fin y el progreso", para dejarse marcar por "la verdad del tiempo reversible". ORO.

No es una casualidad esa vinculación del máximo valor barroco, el oro, con la mentada verdad del tiempo reversible. Potlatch (2004) es el título de uno de los libros posteriores de Carrera, recordemos, y antes de ese libro, otro se llama Oro (1975). ${ }^{18}$ Llegando al cero de la enunciación autoral, vaciamiento permitido por un panel cosmológico en que el lector determina recorridos y monta sentidos, se escuchan los ecos de voces colectivas. Tal vez por eso se lee de los dos lados del eje vertical de Momento de simetría:

\section{COROCEROORO CORO CERO ORO}

Figuras 6 y 7. Fragmentos de Momento de simetría (CARRERA, 1973, [s.p.]).

Es decir, se lee el valor de "más de una lengua",19 el oro del coro que viene después del vacío originario y se pauta por indicios o vestigios, por entradas del ambiente en un texto que no nos da significados sino gestos, conmociones. Una parábasis. Un mapa cósmico e indiciario.

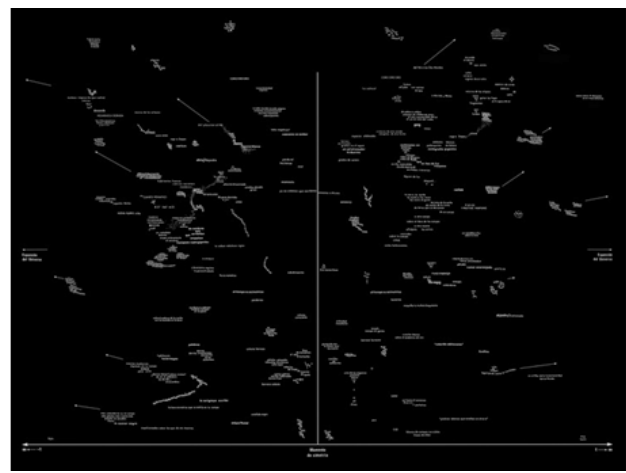

Figura 8. Momento de simetría (CARRERA, 1973, [s.p.]).

18 Una numerosa tradición crítica se refiere a la economía general de y en la poesía de Carrera, así como a la relación entre esa economía, la infancia, el erotismo, lo colectivo y el vaciamiento autoral. A ese respecto, cf. Wolff (2005); Porrúa (2006); Correa (2016); Ros Maturro (2010; 2015); Chejfek (2014).

19 Esa es una de las más felices “definiciones" de deconstrucción (DERRIDA, 2009, [s.p.]). Remate de Males, Campinas-SP, v. 37, n. 1, pp. 345-367, jan./jun. 2017 


\section{VESTIDOS DE ROSA}

A estória não quer ser história. A estória, em rigor, deve ser contra a História.

(Guimarães Rosa, Tutameia, 1967)

Es sintomático que Carrera se haya interesado por Grande Sertão: veredas, pues es una narrativa cosmológica. Un sertão que es centro, para el caso de la cultura brasileña, así como la pampa lo es para la argentina. Exceso: "Ser-tão", diría Francis Utéza (1994) en Metafisica do Grande sertão; "Para una metafísica de la pampa", es el título del ensayo de Carlos Astrada (1944). Alicia y (a)licia, de los dos lados del espejo. Volveré sobre eso.

El oro también está en "O recado do morro", por ejemplo, en el nombre del protagonista Pedro Orósio, alguien que logra descifrar un mensaje remontándolo no a su origen, sino a sus diversas ocurrencias y repeticiones. Ese relato, que está en Corpo de baile (1956), es también un relato cosmológico, como lo describe José Miguel Wisnik (1998) en el ensayo "Recado da viagem". Siete bobos o lunáticos recaderos, siete vaqueros y siete haciendas marcan el desarrollo de la trama, que consiste en un viaje en que se desarrolla la progresiva atribución de sentido para una profecía. Un coro, precisamente, que transporta un significante despojado de centralidad semántica. Ese viaje por el Ser-tão corresponde a un trayecto celeste y telúrico, marcado por los nombres de los hacendados y de los vaqueros, que se vinculan a los nombres de siete planetas del sistema solar y a algunas atribuciones alquímicas para los elementos convencionalmente asociados a esos planetas. El siguiente cuadro presenta sinópticamente esas correspondencias:

\begin{tabular}{|c|c|c|c|}
\hline Hacendados & Vaqueros & Planeta/Elemento & $\begin{array}{c}\text { Bobos/lunáticos/ } \\
\text { recaderos }\end{array}$ \\
\hline Apolinário & $\begin{array}{c}\text { Hélio Dias } \\
\text { Nemes }\end{array}$ & Sol/Oro & Gorgulho \\
\hline Nhá Selena & João Lualino & Luna/Plata & Catraz \\
\hline Marciano & Martinho & Marte/Hierro & Joãozezim \\
\hline Nhô Hermes & Zé Azougue & Mercurio/Mercurio & Guégue \\
\hline Jove & Jovelino & Júpiter/Estaño & Nominedômine \\
\hline Dona Vininha & Veneriano & Venus/Cobre & Coletor \\
\hline Juca Saturno & Ivo Crônico & Saturno/Plomo & Laudelim Pulgapé \\
\hline
\end{tabular}


No me puedo detener en los pormenores de esa narrativa, pero vale la pena destacar que los extremos del viaje -Apolinário/Hélio/Sol/Oro; Juca Saturno/Ivo Crônico/Saturno/Plomo- corresponden también a los centros (uno visible, otro obturado) de la cosmología kepleriana, que para Sarduy es el esquema elíptico del barroco. ${ }^{20}$ También coinciden, esos extremos de la narrativa rosiana, con los dos lados del esquema en espejo Momento de simetría. Oro y excremento, viaje celestial y telúrico, $\infty<\mathrm{t} \mathrm{y}$ $\mathrm{t}>\infty$, alfa y omega, lejos y muy lejos, Alicia y (a)licia.

César Aira (apud AGUILAR, 200o, p. 127, traducción nuestra) también se interesó por estas derivas telúrico-celestiales, como se puede inferir de una entrevista de 1995, en que declara:

\begin{abstract}
Con El vestido rosa quería escribir un cuento, cosa que nunca pude hacer. Debo tener algo geneticamente incompatible con el cuento. Lo que hice entonces fue tomar un cuento que me gusta mucho: "O recado do morro", de Guimarães Rosa. Lo que hay allí es un mensaje que se va transmitiendo, yo lo materializé en el vestidito, pero es sólo un ejercício.
\end{abstract}

Más que eso. Desde mi punto de vista, Aira integra, entre otros, procedimientos tanto del Locus solus de Raymond Roussel (1914) ${ }^{21}$ como de "O recado do morro" (ROSA, 1965) en El vestido rosa (AIRA, 1984), texto cuya elaboración y publicación casi coinciden con el fin de la dictadura militar argentina. En el "cuento" de Aira, de hecho, un puro significante sin utilidad definida circula por el espacio infinito de la pampa sus hilos rosados, sin envejecer ni cambiar. Al final, Asís, un bobo salomónico, ${ }^{22}$ transfigurado en Juez de Paz, apropia el vestido rosa y le da su sentido, digamos, definitivo.

\footnotetext{
20 "El apogeo de la elipsis en el espacio simbólico de la retórica, su exaltación gongorina, coincide con la imposición de su doble geométrico, la elipse, en el discurso astronómico: la teoría kepleriana. En la figura retórica, en la economía de su potencia significante, se privilegia, en un proceso de doble focalización, uno de los focos en detrimento de otro. La elipsis, en sus dos versiones, aparece dibujada alrededor de dos centros: uno visible (el significante marcado /el Sol), que esplende en la frase barroca; otro obturado (el significante oculto/ el centro virtual de la elipse de los planetas), elidido, excluido, el oscuro" (SARDUY, 1999, p. 1.232, grifo do autor). Vale la pena recordar que para Aby Warburg (2010, p. 171), em su conferencia sobre Franz Boll, de 1925, la elipse kepleriana era la figura en que mejor se representaba la bipolaridad de la cultura occidental -siempre aprisionada en la tensión entre el caos de la excitación patética producida por los objetos (un polo dionisíaco) y el distanciamiento de esos objetos reclamado por la razón (el polo apolíneo).

21 Cf. nota 12 de este trabajo.

22 Recuérdese que el nombre del rey Salomón se asocia comúnmente con la alquimia y con el ocultismo.
}

Remate de Males, Campinas-SP, v. 37, n. 1, pp. 345-367, jan./jun. 2017 
Nótese el color rosado, que puede remitir a Roussel, a Guimarães Rosa, a Borges. Ese rosado borgiano tiene su antecedente más destacado en el libro El idioma de los argentinos, de 1928, específicamente en el díptico "Dos esquinas", en que se vinculan las narrativas "Sentirse en muerte" y "Hombres pelearon", díptico que adelanta los temas e imágenes que posteriormente constituirían Evaristo Carriego (1930) y, claro está, "Hombre de la esquina rosada" (1935). Ese díptico, como sabemos, retornaría en textos tan importantes como "Historia de la eternidad" (1936) o "Nueva refutación del tiempo" (1952). En "Sentirse en muerte", el narrador-Borges relata, no una aventura, sino una "experiencia" de la eternidad, una negación radical del tiempo entendido como curso universal. Esa negación que, como sabemos, constituye uno de los fundamentos de las teorías de la física moderna, no tiene como escenario un lugar indiferente, sino una localidad bonaerense, una orilla, Barracas, concretamente una "calle [...] de barro elemental, barro de América no conquistado aún” (BORGES, 1928, p. 150). Ante un modesto muro rosado, el narrador constata: "El tiempo, si podemos intuir esa identidad, es una delusión: la indiferencia e inseparabilidad de un momento de su aparente ayer y otro de su aparente hoy, bastan para desintegrarlo" (p. 150).

Vale la pena pensar que en las ficciones mencionadas -Aira, Roussel, Carrera, Rosa, Borges- el espacio representado propaga o prolifera un contenido "nuclear" que, sin embargo, precisa de sus manifestaciones contingentes para completarse, siquiera suplementariamente, como sentido. Ese núcleo puede llamarse vestido, recado, muro o locus, es indiferente, pues son objetos (a), objetos de deseo que permiten la proliferación significante que precariamente denominamos ficción. El espacio literario es, en esos textos, el "centro" de la representación, un desierto mapeado, un trazado de derivas que no hace otra cosa que evidenciar la posibilidad de rutas infinitas, al tiempo que vacía el sentido de los centros. Mapas del tesoro cuyo tesoro son los propios mapas. Oro, la verdad del tiempo reversible: la plenitud de un vacío, llámese ser-tão, ${ }^{23}$

23 "En Oriente se diría que el saber en sí mismo es un estado del cuerpo, es decir, un ser compuesto, una simulación de ser -de ser ese saber- , que no hace más que recordar el carácter de simulación de todo ser -al manifestarse como ese ser. [...] Reverso del saber que se posee [...] en Oriente encontramos, en el centro de las grandes teogonías -budismo, taoísmo-, no una presencia plena, dios, hombre, logos, sino una vacuidad germinadora cuya metáfora y simulación es la realidad visible, y cuya vivencia y comprensión verdaderas son la liberación.// Es el vacío, o el cero inicial, el que en su mímesis y simulacro de forma proyecta un uno del cual partirá toda la serie de los números y de las cosas, estallido inicial no de un átomo de hipermateria -como los postulan las teorías cosmológicas actuales- 
pampa, vestido o recado, la contingencia de un recado que apenas sirve como vestido para una situación singular.

No sólo el tiempo o el espacio se ven conmocionados por esas narrativas. Hayen ellas una característica inestabilidad genérica. En Borges, sabemos, la inestabilidad está entre el ensayo y el cuento; en Roussel entre la ficción y el procedimiento que la produce casi automáticamente (AIRA, 2016). En Aira y Rosa es más explícita, pues Rosa en los índices de Corpo de baile (ROSA, 1956) enmaraña las cosas llamando sus textos "novela", "conto", "poema” y "romance", y Aira (1984) pone "cuento" en El vestido rosa, que tiene casi 90 páginas, mientras que, en el mismo libro, pone "novela" frente a "Las ovejas", un texto de 55 páginas (AGUILAR, 2000). Notemos, de nuevo: las iglesias cismáticas reunificándose, los géneros confundiéndose como el espacio y el tiempo en la cuarta dimensión, Carrera (1973, [s.p.]) llamando a su poema "figura":24 "el triunfo de la imagen, la verdadera, la que viene del fondo del discurso". 25

Pero eso no sería interesante si no hubiese otro tipo de conmociones. Nos quedaríamos en los efectos de una inestabilidad genérica, o estética, abstractas, cuando la cuestión es mucho más situada. El joven Borges, por ejemplo, cuestionaba la prioridad de las culturas europeas de referencia a través del anacronismo, entre otros motivos, porque comprendió su lugar de suramericano y que esa prioridad lo lanzaría indefectiblemente en el menosprecio; es decir, el joven Borges comprende que si el tiempo cronológico es la verdad, su propio papel será fatalmente el atraso (VÉLEZ, 2015). Algo semejante hace Rosa, para quien Dostoievsky, Flaubert y Goethe nacieron en el sertão, mientras que Zola sólo nació en São Paulo. ${ }^{26}$

sino de una pura no-presencia que se trasviste en pura energía, engendrando lo visible con su simulacro" (SARDUY, 1999, pp. 1.271-1.272, grifo do autor).

24 Cf. nota 13 de este trabajo.

25 En 1929, en la revista Documents, Carl Einstein, historiador -cubista, anarquista- del arte, se refería al triunfo de la imagen en un estudio etnológico sobre André Masson: "Na geração atual, são os literatos que capengam lamentavelmente atrás dos pintores" (EINSTEIN, 2016, p. 19).

26 "Goethe nasceu no sertão, assim como Dostoievski, Tolstoi, Flaubert, Balzac; ele era, como os outros que eu admiro, um moralista, um homem que vivia com a língua e pensava no infinito. Acho que Goethe foi, em resumo, o único grande poeta da literatura mundial que não escrevia para o dia, mas para o infinito. Era um sertanejo. Zola, para tomar arbitrariamente um exemplo contrário, provinha apenas de São Paulo. [...] não do ponto de vista filológico e sim do metafísico, no sertão fala-se a língua de Goethe, Dostoievski e Flaubert, porque o sertão é o terreno da eternidade, da solidão, onde Inneres und Ausseres sind nicht mehr zu trennen [O interior e o exterior já não podem ser separados]." (ROSA apud LORENZ, 2009, pp. LIII-LIV).

Remate de Males, Campinas-SP, v. 37, n. 1, pp. 345-367, jan./jun. 2017 
Aira ha operado también una gama de suspensiones de la prioridad ontológica en otra escala, en El vestido rosa y en varias narrativas. Por ejemplo en la historia pringlense de "El Santito" (2013), en que la clásica dicotomía entre la civilización y la barbarie se transforma en un indecidible. -Esa dicotomía fue clásica en la Argentina de Domingo Faustino Sarmiento, como lo fue en el Brasil de Euclides da Cunha, no dejemos eso de lado, así como no debemos dejar de lado que los espacios simbólicos de esa dicotomía se llaman pampa y sertão, centros, elipses-. "El Santito", no por casualidad, cuenta la historia de un bando de cuatreros legendarios, que en mucho se parecen a jagunços, incluso en el hecho de optar entre la aplicación y el abandono de un código de honor casi caballeresco. La leyenda de "El Santito" suspende algo que las ficciones de Rosa -Grande sertão: veredas, "Meu tio o iauaretê" (ROSA, 1961) y otras muchas de esas ficciones-, como algunos de los postulados filosóficos de Oswald de Andrade, ya suspendían: cuando las condiciones de barbarie creadas por la civilización llegan a un nivel absoluto, tal vez lo más civilizado sea deslizarse cuerdamente en la barbarie. Acerca de esa dicotomía, dice Aira en una conferencia sobre la Amalia de José Mármol (2012, p. 29): "Civilización y barbarie serán siempre reversos, nunca anversos".

Vestidos, figuras, recados: centros vacíos que se llenan de sentido en cada una de sus apropiaciones, sustrayendo el sentido absoluto atribuido a representaciones de lo colectivo. Ficciones que comportan la posibilidad escandalosa de "escoger un destino" (AGUILAR, 2000, p. 135). COROCEROORO: llegando al cero del enunciado, y pasando a la enunciación -un vaciamiento permitido por esos paneles cosmológicos en que el lector determina recorridos y monta sentidos-, se escuchan los ecos de voces colectivas, algunas de ellas históricamente silenciadas.

Sorprendentemente, si lo leemos cerca de Aira y de Carrera, y a través de los instrumentos con que ellos lo leyeron, Guimarães Rosa tendría mayor afinidad con protocolos posteriores a aquellos que erigieron la autonomía literaria en un valor ligado a la representación superestructural de un complejo histórico-social latinoamericano sin, entretanto, lograr ver el carácter relativo, es decir ficcional, construido, de aquello que se consideraba dado -lo específico cultural-, o la profunda dogmática del 
progreso implícita en la postulación de un universal transculturado o superregionalizado por una consciencia dilacerada del subdesarrollo. El anacronismo fabrica la historia: proyectada sobre la escena contemporánea, más acá de esos diagnósticos que la entendían como precursora de la literatura latinoamericana posterior a la Segunda Guerra Mundial, la escritura de Rosa tendría la potencia barroca o acefálica de colocarse, no como simple receptora de un contexto, sino como creadora intempestiva de contextos en una situación de entre-lugar que, por su propio carácter derivado -y no- en relación con las metrópolis coloniales, impugnaría cualquier pretensión de prioridad ontológica, centralidad o autenticidad absolutas de una cultura de referencia o, siquiera, de un significado esencial.

Nótese que, lejos de una reacción nacionalista o estatal, las escrituras mencionadas incorporan al vacío, a la ficción, como fundamentos, haciendo en adelante que el texto evidencie su propia legibilidad como consecuencia de su inscripción en una red intertextual, tan amplia como variables son sus lecturas, un marco de referencia en perpetuo movimiento. Con esto a la vez se impugna una exigencia regionalista rasa y se cuestiona un universalismo cerrado a diálogos de afinidad, pues dislocando los marcos perceptivos otras constelaciones aparecen: no hay, así, ni un origen absoluto ni un destino universal, sino apenas lugares de existencia, que desactivan cualquier noción de precedencia espiritual o de una medida absoluta de valor para los fenómenos culturales.

En ese sentido, la constelación opera como un poderoso antídoto contra el etnocentrismo, además de que, de una manera clara, desmonta cualquier pretensión autonomista, pues al mostrar el acto de lectura como dependiente de un marco referencial pasible de infinitas derivas se despoja al texto de una centralidad semántica. Toda lectura es la ficción de una lectura, y está fuertemente relacionada con imperativos vitales, con opciones de lectura en el laberinto, o desierto, de los significantes; derivas que, de ninguna manera, podemos separar de nuestras aproximaciones a los textos. De esta manera, entre otras cosas, podemos comprender que un pensamiento de los fenómenos y prácticas culturales debe tener en cuenta que esos fenómenos y prácticas no pueden ser definidos a partir de referentes homogéneos, porque ese tipo de operación refuerza hábitos y relaciones de poder que afectan la definición de sus propios "objetos".

Incluso pegados como con una cinta adhesiva en una exposición de poemas ilustrados, los mapas cosmológicos de nuestros dos monjes -que 
son tres, cuatro o cinco- hablan "más de una lengua" y se encuentran en un cielo astronómico, telúrico, que es un cielo-paraíso: la simultaneidad o el don de lo no simultáneo que, con José Triano, podríamos denominar "el cielo cubista".

\section{REFERENCIAS BIBLIOGRÁFICAS}

AGUILAR, Gonzalo. Aira/Rosa: um vestido e um recado. In: SANTOS, Luiz Alberto Brandão \& PEREIRA, Maria Antonieta (eds.). Trocas culturais na América Latina. Belo Horizonte: Pós-Lit/FALE/UFMG, 2000, pp. 123-139.

AIRA, César. El vestido rosa. Las ovejas. Buenos Aires: Ada Korn Editora, 1984.

AIRA, César. Los fantasmas. Buenos Aires: Grupo Editor Latinoamericano, 1990.

AIRA, César. Epílogo-haiku. In: CARRERA, Arturo. Carpe diem. México: ICOCULT, 2003, pp. 81-91.

AIRA, César. Amalia. Cuadernos Hispanoamericanos, no 743, 2012, pp. 25-35.

AIRA, César. Tres historias pringlenses. Buenos Aires: Ediciones Biblioteca Nacional, 2013.

AIRA, César. Continuación de ideas diversas. Santiago de Chile: Ediciones Universidad Diego Portales, 2014a.

AIRA, César. Triano. Buenos Aires: Alto Pogo / Milena Caserola / El 8o Loco, 2014b.

AIRA, César. Raymond Roussel. A chave unificada. Trad. Byron Vélez Escallón. Florianópolis: Cultura e Barbárie, 2016.

ANTELO, Raúl. Crítica acéfala. Buenos Aires: Editorial Grumo, 2008.

ANTELO, Raúl. Maria com Marcel. Duchamp nos trópicos. Belo Horizonte: Editora UFMG, 2010.

ANTELO, Raúl. Poesia e modernismo: pré-lógica, formal, dialética e pós-lógica. Revista IEB, no 55, 2012, pp. 43-57.

ANTELO, Raúl. Miró e a iminência do não-poder. Crítica cultural, v. 11, no 2, 2016, pp. 187192.

BATAILLE, Georges. La parte maldita. Trad. Lucía Ana Belloro y Julián Manuel Fava. Buenos Aires: Las Cuarenta, 2009.

BORGES, Jorge Luis. El idioma de los argentinos. Buenos Aires: M. Gleizer, 1928. 
BORGES, Jorge Luis. Nueva refutación del tiempo. In: . Obras completas II (19521972). Buenos Aires: Emecé, 2010, pp. 121-133.

CANDIDO, Antonio. Literatura e subdesenvolvimento. In: A educação pela noite e outros ensaios. São Paulo: Ática, 1987, pp. 140-162.

CANDIDO, Antonio. O homem dos avessos. In: COUTINHO, Eduardo (org.). Fortuna crítica no 6, Guimarães Rosa. São Paulo: Civilização brasileira, 1991, pp. 294-309.

CANDIDO, Antonio. A literatura e a formação do homem. In: . Textos de intervenção. São Paulo: Duas Cidades, 2002, pp. 77-92.

CARRERA, Arturo. Momento de simetría. Buenos Aires: Sudamericana, 1973.

CARRERA, Arturo. Vigilámbulo. Poesia reunida. Vol. III. Buenos Aires: Adriana Hidalgo, 2014.

CERA, Flávia. Jantar felicidade: os zumbis e seus nomes. Revista Landa, Florianópolis, v. 2, no 2, 2014, pp. 187-196.

CHEJFEK, Sergio. El estribillo de la experiencia. In: CARRERA, Arturo. Vigilámbulo. Poesia reunida. Vol. I. Buenos Aires: Adriana Hidalgo, 2014, pp. 11-53.

CLIFFORD, James. A experiência etnográfica: antropologia e literatura no século XX. Rio de Janeiro: Editora UFRJ, 2008.

CONTRERAS, Sandra. Las vueltas de César Aira. Rosario: Beatriz Viterbo, 2002.

COSTA LIMA, Luiz. A linguagem da crítica. Correio da manhã, 4 de fevereiro de 1968, [s.p.].

COSTA LIMA, Luiz. O mundo em perspectiva: Guimarães Rosa. In: ROSA, João Guimarães. Ficção completa. Rio de Janeiro: Editora Nova Aguilar, 2009, pp. CCXVI-CCXXIX.

CORREA, Joaquín. Entonações da intensidade. Sobre uma (última) partícula do poema em Paulo Leminski e Arturo Carrera. Dissertação de Mestrado em Literatura. Universidade Federal de Santa Catarina, Centro de Comunicação e Expressão, Florianópolis, 2016.

DERRIDA, Jacques. Margens da filosofia. São Paulo: Papirus, 1991.

DERRIDA, Jacques. El monolinguismo del otro o la prótesis de origen. Trad. Horacio Pons. Buenos Aires: Manantial, 2009.

DIDI-HUBERMAN, Georges. Ante el tiempo: historia del arte y anacronismo de las imágenes. Trad. Antonio Oviedo. Buenos Aires: Adriana Hidalgo Editora, 2006.

EINSTEIN, Carl. Documents: 1929. Trad. Takashi Wakamatsu. Florianópolis: Cultura e Barbárie / Armazém, 2016. 
HARSS, Luis. Los nuestros. Buenos Aires: Editorial Sudamericana, 1966.

KLINGER, Diana. Escritas de si, escritas do outro (o retorno do autor e a virada etnográfica: Bernardo Carvalho, Fernando Vallejo, Washington Cucurto, João Gilberto Noll, César Aira, Silviano Santiago). Rio de Janeiro: 7Letras, 2007.

KLINGER, Diana. Escrita de si como performance. Revista Brasileira de Literatura Comparada, no 12, 2008, pp. 11-30.

LADDAGA, Reinaldo. Espectáculos de realidad. Ensayos sobre la narrativa latinoamericana de las últimas décadas. Rosario: Beatriz Viterbo, 2007.

LAHUERTA, Juan José. Marginalia: Aby Warburg; Carl Einstein. Madrid: Ediciones Asimétricas, 2015.

LORENZ, Günter. Diálogo com Guimarães Rosa. In: ROSA, João Guimarães. Ficção completa. Vol. I. Rio de Janeiro: Editora Nova Aguilar, 2009, pp. XXXI-LXV.

LUDMER, Josefina. Literaturas posautónomas. Ciberletras, no 17, jul. 2007. Disponible en: <http://www.lehman.cuny.edu/ciberletras/vi7/ludmer.htm>. Acceso en: 20 jul. 2012.

LUDMER, Josefina. Notas para literaturas posautónomas III. Blog de Josefina Ludmer, 31 julio 2010. Disponible en: <http://josefinaludmer.wordpress.com/2010/o7/31/notaspara-literaturas-posautonomas-iii/>. Acceso en: 20 dic. 2012.

PORRÚA, Ana. Prólogo. La cuenta de las sensaciones. In: CARRERA, Arturo. Animaciones suspendidas. Antología poética. Mérida: Ediciones el otro el mismo, 2006, pp. 11-33.

PREMAT, Julio. Héroes sin atributos. Figuras de autor en la literatura argentina. Buenos Aires: Fondo de Cultura Económica, 2009.

RAMA, Ángel. Transculturación narrativa en América Latina. Buenos Aires: Ediciones El Andariego, 2008.

RODRÍGUEZ MONEGAL, Emir. Narradores de esta América. Argentina: Edición Carabela, 1969.

ROSA, João Guimarães. O recado do morro. In: No Urubuquaquá, no Pinhém [Corpo de baile, 1956]. Rio de Janeiro: José Olympio, 1965, pp. 3-70.

ROSA, João Guimarães. Tutameia. Rio de Janeiro: José Olympio, 1968.

ROSA, João Guimarães. Grande sertão: veredas. Rio de Janeiro: José Olympio, 1976.

ROS MATTURRO, Ofelia. El billete asomaba como fuego rojo: dinero y goce en la poesía de Arturo Carrera. Borromeo, Instituto de Investigaciones en Psicoanálisis Aplicadas a las Ciencias Sociales, v. 1, 2010. Disponible en: <http://borromeo.kennedy.edu.ar/ Paginas/2010-01/Sumario.aspx>. Acceso en: 23 mayo 2016. 
ROS MATTURRO, Ofelia. La infancia extrañando al dinero y al lenguaje en Potlatch de Arturo Carrera. Revista Iberoamericana, jun. 2015, pp. 315-332. Disponible en: <http://revista-iberoamericana.pitt.edu/ojs/index.php/Iberoamericana/article/ view/7266>. Acceso en: 23 mayo 2016.

SANTIAGO, Silviano. Uma literatura nos trópicos. São Paulo: Editora Perspectiva, 1978.

SANTOS, Antonio Carlos. Entre a imobilidade e o movimento. As estratégias do senhor Aira. Revista Landa, Florianópolis, v. 2, no 2, 2014, pp. 197-205.

SARDUY, Severo. Obra completa. Paris: Unesco / Madrid: ALLCA XX / México: Fondo de Cultura Económica, 1999.

SARDUY, Severo. La noche escribe. In: CARRERA, Arturo. Vigilámbulo. Poesia reunida. Vol. III. Buenos Aires: Adriana Hidalgo, 2014, pp. 539-540.

VÉLEZ ESCALLÓN, Bairon. O “Páramo” é do tamanho do mundo: Guimarães Rosa, Bogotá, Iauaretê. Tese de Doutorado em Literatura. Universidade Federal de Santa Catarina, Centro de Comunicação e Expressão, Florianópolis, 2014.

VÉLEZ ESCALLÓN, Bairon. Borges 4D. Variaciones Borges, v. 40, 2015, pp. 115-132.

VÉLEZ ESCALLÓN, Bairon. JGR-4D: “O espelho”, um despetalar de Rosa. Cuadernos del CILHA, v. 1, 2016, pp. 1-20.

WARBURG, Aby. Atlas Mnemosyne. Trad. Joaquín Chamorro Mielke. Martin Wanke (ed.). Madrid: Akal, 2010.

WISNIK, José Miguel. Recado da viagem. Scripta, Belo Horizonte, v. 2, no 3, 2º sem., 1998, pp. 16o-170.

WOLFF, Jorge. Arturo Carrera: o ouro do sentido. Oroboro, Curitiba, no 4, jun./jul./ago. 2005, pp. 34-37.

WOLFF, Jorge. Autografia: pensador airado. Revista Landa, Florianópolis, v. 2, no 2, 2014, pp. 217-227.

WOLFF, Jorge. Poesia e vida em Arturo ou Câmbio de ideia no 2 ou Lo creo porque es absurdo. In: SCRAMIM, Susana (org.). Alteridades na poesia. Riscos, aberturas, sobrevivências. São Paulo: Iluminuras, 2016, pp. 53-62. 